\title{
Coraliomargarita akajimensis gen. nov., sp. nov., a novel member of the phylum 'Verrucomicrobia' isolated from seawater in Japan
}

Correspondence
Jaewoo Yoon
aa57058@mail.ecc.u-tokyo.ac.jp

\author{
Jaewoo Yoon, ${ }^{1}$ Mina Yasumoto-Hirose, ${ }^{2} \dagger$ Atsuko Katsuta, ${ }^{2}$ \\ Hiroshi Sekiguchi, ${ }^{2}$ Satoru Matsuda, ${ }^{2}$ Hiroaki Kasai ${ }^{2}$ and Akira Yokota $^{1}$ \\ ${ }^{1}$ Institute of Molecular and Cellular Biosciences, The University of Tokyo, 1-1-1 Yayoi, \\ Bunkyo-Ku, Tokyo 113-0032, Japan \\ ${ }^{2}$ Marine Biotechnology Institute Co. Ltd, 3-75-1, Heita, Kamaishi, Iwate 026-0001, Japan
}

\begin{abstract}
An obligately aerobic, Gram-negative, non-spore-forming, non-motile, spherical bacterium, designated strain 04OKA010-24 ${ }^{\top}$, was isolated from seawater surrounding the hard coral Galaxea fascicularis L., collected at Majanohama, Akajima, Japan, and was subjected to a polyphasic taxonomic study. Phylogenetic analyses based on the 16S rRNA gene sequence indicated that the new strain represented a member of the phylum 'Verrucomicrobia' and shared 84-95\% sequence similarity with cultivated strains of 'Verrucomicrobia' subdivision 4. Amino acid analysis of the cell-wall hydrolysate indicated the absence of muramic acid and diaminopimelic acid, which suggested that the strain did not contain peptidoglycan in the cell wall. The $G+C$ content of the DNA was 53.9 mol\%. MK-7 was the major menaquinone and $\mathrm{C}_{14: 0}, \mathrm{C}_{18: 1} \omega 9 \mathrm{c}$ and $\mathrm{C}_{18: 0}$ were the major fatty acids. On the basis of these data, it was concluded that strain 04OKA010-24 ${ }^{\top}$ represents a novel species in a new genus in subdivision 4 of the phylum 'Verrucomicrobia', for which the name Coraliomargarita akajimensis gen. nov., sp. nov. is proposed. The type strain of Coraliomargarita akajimensis is $04 \mathrm{OKA010}-24^{\top}\left(=\mathrm{MBIC}^{\mathrm{N}} 6463^{\top}=\mathrm{IAM} 15411^{\top}=\mathrm{KCTC}\right.$ $\left.12865^{\top}\right)$.
\end{abstract}

Molecular phylogenetic approaches based on 16S rRNA gene sequence analysis have revealed that members of the phylum 'Verrucomicrobia' (Hedlund et al., 1997; Hugenholtz et al., 1998), a phylum represented by very few cultivated strains, are a globally distributed, abundant group of bacteria that are increasingly recognized as being of environmental significance (Sangwan et al., 2005). The phylum 'Verrucomicrobia' has been informally classified into subdivisions $1-5$ by Hugenholtz et al. (1998), and has also been classified into subdivisions 1-6 by Vandekerckhove et al. (2000). At the time of writing, only three of these subdivisions are recognized by Bergey's Manual of Systematic Bacteriology (Garrity \& Holt, 2001), all three corresponding to the rank of family: Verrucomicrobiaceae (subdivision 1), Opitutaceae (subdivision 4) and 'Xiphinematobacteriaceae' (subdivision 2) (Sangwan et al., 2005). Subdivision 4 comprises just a few recognized representatives, such as Opitutus terrae $\mathrm{PB} 90-1^{\mathrm{T}}$ and related strains (Janssen et al., 1997; Chin et al., 1999, 2001), which have been isolated from soil

tPresent address: Okinawa Prefecture Collaboration of Regional Entities for the Advancement of Technological Excellence, JST. Okinawa Health Biotechnology Research Development Center, 12-75 Suzaki, Uruma Okinawa 904-2234, Japan.

The GenBank/EMBL/DDBJ accession number for the 16S rRNA gene sequence of strain 04OKA010-24 $4^{\top}$ is AB266750. environments, and the marine bacteria 'Fucophilus fucoidanolyticus' SI-1234 (Sakai et al., 2003) and Alterococcus

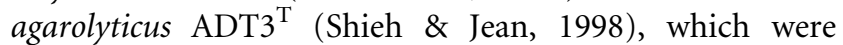
isolated from thermal springs. A. agarolyticus was misclassified as a member of the class Gammaproteobacteria (Sangwan et al., 2004).

A specimen of the hard coral Galaxea fascicularis L. was collected from 3-5 $\mathrm{m}$ below the surface of the sea at Majanohama, Akajima, Japan, in March 2004 together with the seawater around the coral, and these were kept in a $500-\mathrm{ml}$ plastic bottle for $2-5 \mathrm{~h}$. Strain 04OKA010-24 ${ }^{\mathrm{T}}$ was isolated from the seawater in the sample bottle. The seawater was diluted $1: 10$ with filtered, autoclaved seawater and used for isolation on $1: 10$ diluted marine agar [3.74 g marine broth 2216 (Difco), $750 \mathrm{ml}$ filtered seawater, $250 \mathrm{ml}$ distilled water, $15 \mathrm{~g}$ agar]. The phylogenetic position of strain 04OKA010-24 ${ }^{\mathrm{T}}$ was investigated by using a polyphasic taxonomic approach including 16S rRNA gene sequence analysis, together with physiological, biochemical and chemotaxonomic analyses. Based on these data, it is proposed that the isolate represents a novel species of a new genus in the phylum 'Verrucomicrobia'.

The temperature range and $\mathrm{pH}$ range for growth were determined by incubating the isolate in marine agar 2216 


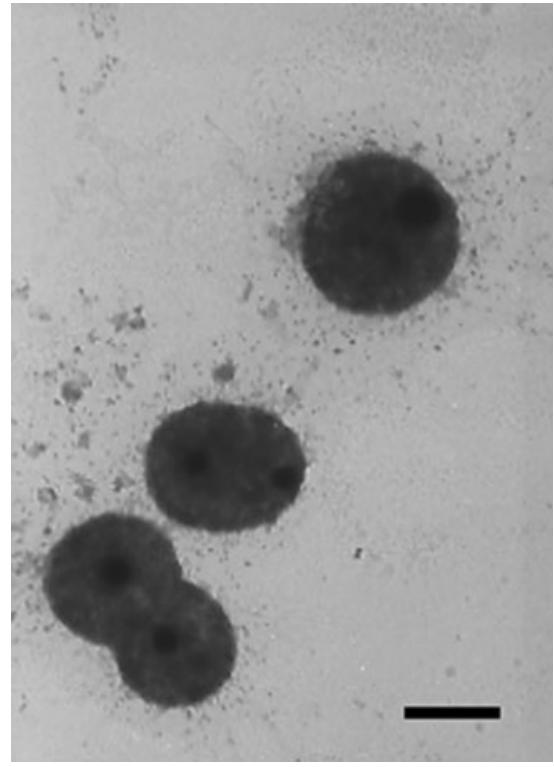

Fig. 1. Transmission electron micrograph of negatively stained cells of strain 04OKA010-24 $4^{\top}$. Bar, $500 \mathrm{~nm}$.

(MA; Difco). The following buffers were used for $\mathrm{pH}$ tests in MA: MES (pH 5.5), ACES ( $\mathrm{pH} 6.5$ and 7.0), TAPSO $(\mathrm{pH}$ 7.6), TAPS ( $\mathrm{pH} 8.5)$ and CHES ( $\mathrm{pH} 9.0$ and 9.5). Gram staining was performed as described by Murray et al. (1994). Cell morphology was observed by using light microscopy (BX60; Olympus) and transmission electron microscopy (TEM). For TEM observation, cells were mounted on Formvar-coated copper grids and negatively stained with $2 \%(\mathrm{w} / \mathrm{v})$ aqueous uranyl acetate. Grids were observed in an H-7000 transmission electron microscope (Hitachi) operated at $75 \mathrm{kV}$. In the course of TEM, cells of various sizes were observed. Cells were coccoid and generally $0.5-1.2 \mu \mathrm{m}$ in diameter. In the stationary growth phase, smaller cells $(0.5-0.6 \mu \mathrm{m}$ in diameter) were predominantly observed. The cells were non-motile and no flagella were seen by electron microscopy (Fig. 1). Growth under anaerobic conditions was determined after 2 weeks incubation in an AnaeroPack (Mitsubishi Gas Chemical Co., Inc.) on MA. Catalase activity was determined by bubble formation in a $3 \% \mathrm{H}_{2} \mathrm{O}_{2}$ solution. Oxidase activity was determined by use of cytochrome oxidase paper (Eiken Chemical Co., Ltd). API $20 \mathrm{E}$ and API $50 \mathrm{CH}$ strips (bioMérieux) were used to determine the physiological and biochemical characteristics of strain 04OKA010-24 ${ }^{\mathrm{T}}$. These were read after incubation at $30^{\circ} \mathrm{C}$ for 48 and $72 \mathrm{~h}$, respectively. Determination of the respiratory quinone system and cellular fatty acid composition was carried out as described by Katsuta et al. (2005). DNA was prepared by using Genomic tips (Qiagen) from cells grown in DSM medium no. 607, and the DNA base composition was determined by using the HPLC method of Mesbah et al. (1989). Cell walls were prepared by the methods described by Schleifer \& Kandler (1972), and amino acids in an acid hydrolysate of the cell walls were identified by TLC (Harper \& Davis, 1979) and by HPLC, as their phenylthiocarbamoyl derivatives, with a model LC-10AD HPLC apparatus (Shimazu) equipped with a Wakopak WS-PTC column

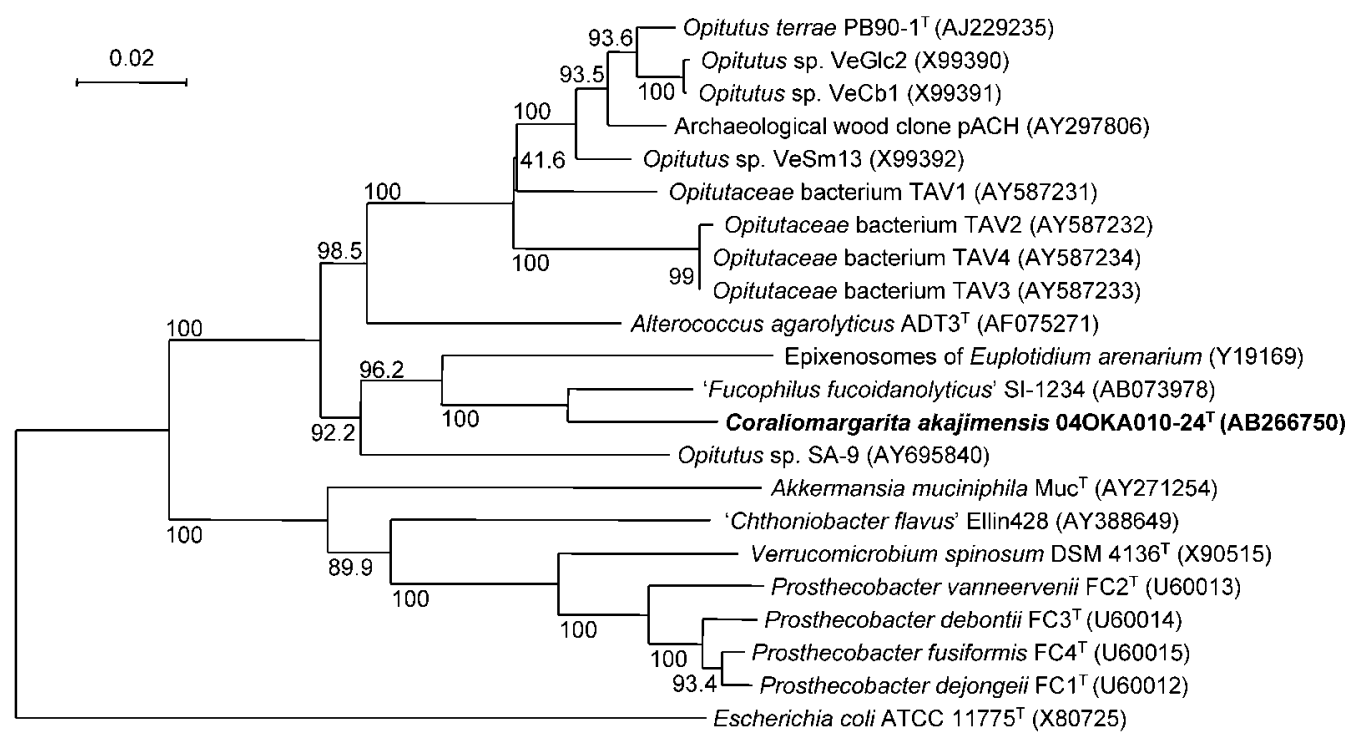

Fig. 2. Phylogenetic tree showing the position of strain $04 O K A 010-24^{\top}$ in relation to representative $16 \mathrm{~S}$ rRNA gene sequences that include the currently known phylogenetic diversity within subdivision 4 of the phylum 'Verrucomicrobia'. The tree, which was rooted using recognized representatives and Escherichia coli ATCC $11775^{\top}$ as the outgroup, was generated by the neighbour-joining method. Numbers at nodes indicate the occurrence of the strain in 1000 bootstrapped trees; only values greater than $40 \%$ are shown. Bar, $2 \%$ sequence divergence. 
(Wako Pure Chemical Industries) (Yokota et al., 1993). An approximately $1500 \mathrm{bp}$ fragment of the $16 \mathrm{~S}$ rRNA gene was amplified from the extracted DNA by using bacterial universal primers 27F and 1492R (Weisburg et al., 1991) specific to the $16 \mathrm{~S}$ rRNA gene. To ascertain the phylogenetic position of the new isolate, the $16 \mathrm{~S}$ rRNA gene sequence of strain 04OKA010-24 ${ }^{\mathrm{T}}$ was compared with sequences obtained from GenBank (National Center for Biotechnology Information; http://www.ncbi.nlm.nih.gov). Multiple alignments of the sequences were performed by using CLUSTAL_X (version 1.83) (Thompson et al., 1997). Alignment gaps and ambiguous bases were not taken into consideration when 1213 bases of the 16S rRNA gene nucleotides were compared. Phylogenetic relationships were analysed by using the same software. Distances were calculated by using the two-parameter model of Kimura (1980). Clustering with the neighbour-joining method (Saitou \& Nei, 1987) was determined by using bootstrap values based on 1000 replications (Felsenstein, 1985).
Sequence similarity values were calculated via MEGA3 (Kumar et al., 2004).

On the basis of 16S rRNA gene sequence analysis, strain 04OKA010-24 ${ }^{\mathrm{T}}$ was found to be related most closely to the as yet undescribed marine bacterium 'Fucophilus fucoidanolyticus' SI-1234 (94.8\% similarity). The most closely related type strains of species with validly published names were Alterococcus agarolyticus $\mathrm{ADT}^{\mathrm{T}}$ (87.6\% similarity) and Opitutus terrae PB90-1 ${ }^{\mathrm{T}}$ (83.9\%). Based on levels of $16 \mathrm{~S}$ rRNA gene sequence divergence, strain 04OKA010- $24^{\mathrm{T}}$ is thus determined to be related to the genera Alterococcus and Opitutus, which are members of 'Verrucomicrobia' subdivision 4 . These results indicate that strain 04OKA010-24 ${ }^{\mathrm{T}}$ belongs to the phylum 'Verrucomicrobia' within subdivision 4 (Fig. 2).

Strain 04OKA010-24 ${ }^{\mathrm{T}}$ also showed distinct phenotypic features that discriminated it from recognized members

Table 1. Characteristics that differentiate strain $040 K A 010-24^{\top}$ from representatives of other genera of subdivision 4 in the phylum 'Verrucomicrobia'

Strains: 1, 04OKA010-24 ${ }^{\mathrm{T}} ; 2$, Alterococcus agarolyticus BCRC $9135^{\mathrm{T}}$ (data from Shieh \& Jean, 1998); 3, Opitutus terrae DSM $11246^{\mathrm{T}}$ (Chin et al., 2001). +, Positive; W, weakly positive; -, negative; ND, no data.

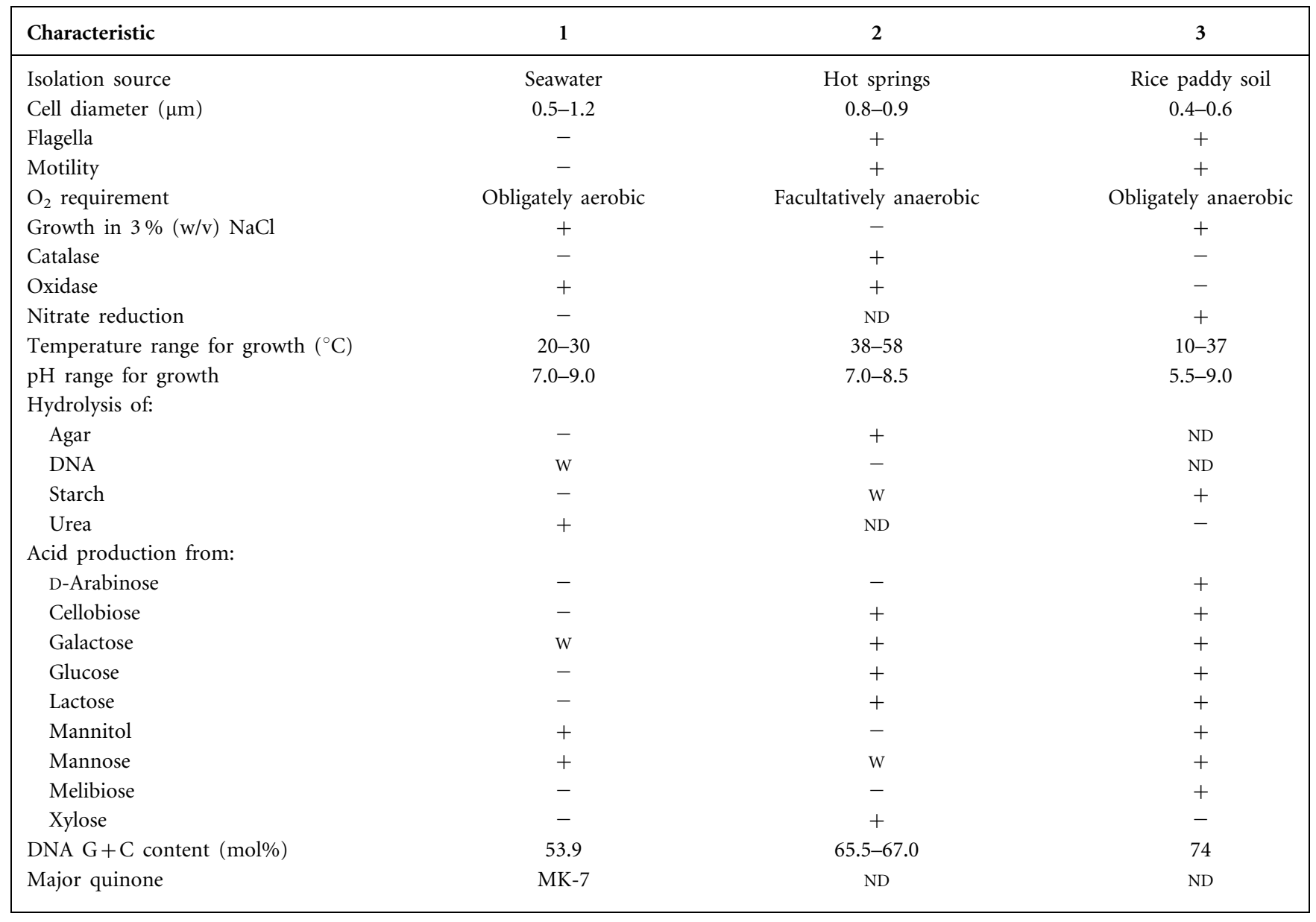


of 'Verrucomicrobia' subdivision 4 (Table 1): cells lacked flagella and were non-motile (Fig. 1).

Biochemical and physiological characteristics of strain 04OKA010-24 ${ }^{\mathrm{T}}$ further supported the phylogenetic results. The major quinone system was menaquinone MK-7. The $\mathrm{G}+\mathrm{C}$ content of the DNA of strain 04OKA010-24 $4^{\mathrm{T}}$ was $53.9 \mathrm{~mol} \%$. Major fatty acids of strain $04 \mathrm{OKA} 010-24^{\mathrm{T}}$ were $\mathrm{C}_{14: 0}(24.2 \%), \mathrm{C}_{18: 1} \omega 9 c(23.5 \%)$ and $\mathrm{C}_{18: 0}(15.6 \%)$. The cell wall was prepared by disrupting cells, followed by heating with $3 \%$ SDS, washing and centrifugation. Amino acid analysis of the cell-wall hydrolysate indicated the absence of muramic acid and diaminopimelic acid, suggesting that the cell wall did not contain peptidoglycan.

Strain 04OKA010-24 $4^{\mathrm{T}}$ was obligately aerobic, was isolated from seawater and was able to tolerate $5 \% \mathrm{NaCl}$; by contrast, the other members of 'Verrucomicrobia' subdivision 4, originating from rice paddy soil and hot springs, could only tolerate up to $1-3 \% \mathrm{NaCl}$. Strain $04 \mathrm{OKA} 010-24^{\mathrm{T}}$ could also be distinguished on the basis of the following characteristics: catalase, oxidase, nitrate reduction, temperature range for growth and hydrolysis of DNA and urea. Some differential characteristics were noted from the API $50 \mathrm{CH}$ results, including acid production from galactose, mannitol and mannose.

Based on the results of the phylogenetic analysis and its biochemical and physiological properties, strain 04OKA010$24^{\mathrm{T}}$ was considered to represent a novel species in a new genus belonging to subdivision 4 of the phylum 'Verrucomicrobia'. We propose the name Coraliomargarita akajimensis gen. nov., sp. nov. for this organism.

\section{Description of Coraliomargarita gen. nov.}

Coraliomargarita (Co.ra'li.o.mar.ga.ri'ta. Gr. n. koralion coral; L. fem. n. margarita a pearl; N.L. fem. n. Coraliomargarita coral pearl, referring to a white-colony-forming, coccoid micro-organism isolated from seawater in a sample bottle of hard coral).

Cells are Gram-negative, obligately aerobic cocci. Cells lack flagella and are non-motile. No spores are formed. Catalasenegative, but oxidase-positive. Nitrate is not reduced. The major respiratory quinone is MK-7. The $\mathrm{G}+\mathrm{C}$ content of the genomic DNA of the type strain of the type species is $53.9 \mathrm{~mol} \%$. Predominant cellular fatty acids are $\mathrm{C}_{14: 0}$, $\mathrm{C}_{18: 1} \omega 9 \mathrm{c}$ and $\mathrm{C}_{18: 0}$. The type species is Coraliomargarita akajimensis.

\section{Description of Coraliomargarita akajimensis sp. nov.}

Coraliomargarita akajimensis (a.ka.ji.men' sis. N.L. fem. adj. akajimensis pertaining to Akajima, an island in Okinawa, from where the type strain was isolated).

Main characteristics are as given for the genus. In addition, cells are $0.5-1.2 \mu \mathrm{m}$ in diameter. Neither cellular gliding movement nor swarming growth is observed. Colonies grown on half-strength R2A agar medium with $75 \%$ artificial seawater are circular, convex and white. The optimum temperature for growth is $20-30^{\circ} \mathrm{C}$; no growth occurs at 4 or $45^{\circ} \mathrm{C}$. The $\mathrm{pH}$ range for growth is 7.0-9.0. $\mathrm{NaCl}$ is required for growth and can be tolerated at up to $5 \%$ $(\mathrm{w} / \mathrm{v})$. Urea and DNA are hydrolysed but agar, casein, aesculin and gelatin are not. Reactions for acetoin, ONPG and tryptophan deaminase are positive, but reactions for citrate utilization, arginine dihydrolase, lysine decarboxylase, ornithine decarboxylase, hydrogen sulfide and indole production are negative. Acid is produced from glycerol, galactose, fructose, mannose, mannitol, sorbitol, trehalose, D-turanose, D-lyxose, D-tagatose, D-fucose, L-fucose, D-arabitol, L-arabitol and 5-ketogluconate, but not from erythritol, D-arabinose, L-arabinose, ribose, D-xylose, L-xylose, adonitol, methyl $\beta$-D-xylopyranoside, glucose, sorbose, rhamnose, dulcitol, inositol, methyl $\alpha$-D-mannnopyranoside, methyl $\alpha$-D-glucopyranoside, $N$-acetylglucosamine, amygdalin, arbutin, salicin, cellobiose, maltose, lactose, melibiose, sucrose, inulin, melezitose, raffinose, starch, glycogen, xylitol, gentiobiose, gluconate or 2-ketogluconate. The usual components of bacterial cell walls such as muramic acid and diaminopimelic acid are not detected. Major fatty acid components $\left(>2.0 \%\right.$ of the total) are iso- $\mathrm{C}_{14: 0}(8.2 \%)$, $\mathrm{C}_{14: 0}(24.2 \%)$, anteiso- $\mathrm{C}_{15: 0}(2.9 \%), \mathrm{C}_{16: 0}(3.3 \%), \mathrm{C}_{18: 1} \omega 9 \mathrm{c}$ $(23.5 \%), \mathrm{C}_{18: 0}(15.5 \%), \mathrm{C}_{19: 0}(2.8 \%)$ and $\mathrm{C}_{21: 0}(6.9 \%)$.

The type strain, 04OKA010- $24^{\mathrm{T}}\left(=\mathrm{MBIC} 06463^{\mathrm{T}}=\mathrm{IAM}\right.$ $15411^{\mathrm{T}}=$ KCTC $12865^{\mathrm{T}}$ ), was isolated from seawater in a sampling bottle of the hard coral Galaxea fascicularis L., collected at Majanohama, Akajima, Japan.

\section{Acknowledgements}

We are grateful to Hiroki Taniguchi of the Akajima Marine Science Laboratory and Minoru Yasumoto for their help in collecting and identifying the hard coral. We thank Drs Kyoko Adachi and Yoshihide Matsuo for their help with the fatty acid, quinone and $\mathrm{G}+\mathrm{C}$ content analyses. We also thank Sachiko Kawasaki, Ayako Matsuzaki, Tomomi Haga, Yukiko Itazawa and Midori Nozawa for their outstanding technical assistance. This work was supported by the New Energy and Industrial Technology Development Organization (NEDO).

\section{References}

Chin, K.-J., Hahn, D., Hengtsmann, U., Liesack, W. \& Janssen, P. H. (1999). Characterization and identification of numerically abundant culturable bacteria from the anoxic bulk soil of rice paddy microcosms. Appl Environ Microbiol 65, 5042-5049.

Chin, K.-J., Liesack, W. \& Janssen, P. H. (2001). Opitutus terrae gen. nov., sp. nov., to accommodate novel strains of the division 'Verrucomicrobia' isolated from rice paddy soil. Int J Syst Evol Microbiol 51, 1965-1968.

Felsenstein, J. (1985). Confidence limits on phylogenies: an approach using the bootstrap. Evolution 39, 783-791.

Garrity, G. M. \& Holt, J. G. (2001). The road map to the Manual. In Bergey's Manual of Systematic Bacteriology, 2nd edn, vol. 1, pp. 119-166. Edited by D. R. Boone, R. W. Castenholz \& G. M. Garrity. New York: Springer. 
Harper, J. J. \& Davis, G. H. G. (1979). Two-dimensional thin-layer chromatography for amino acid analysis of bacterial cell walls. Int J Syst Bacteriol 29, 56-58.

Hedlund, B. P., Gosink, J. J. \& Staley, J. T. (1997). Verrucomicrobia div. nov., a new division of the bacteria containing three new species of Prothecobacter. Antonie van Leeuwenhoek 72, 29-38.

Hugenholtz, P., Goebel, B. M. \& Pace, N. R. (1998). Impact of culture-independent studies on the emerging phylogenetic view of bacterial diversity. J Bacteriol 180, 4765-4774.

Janssen, P. H., Schuhmann, A., Mörschel, E. \& Rainey, F. A. (1997). Novel anaerobic ultramicrobacteria belonging to the Verrucomicrobiales lineage of bacterial descent isolated by dilution culture from anoxic rice paddy soil. Appl Environ Microbiol 63, 1382-1388.

Katsuta, A., Adachi, K., Matsuda, S., Shizuri, Y. \& Kasai, H. (2005). Ferrimonas marina sp. nov. Int J Syst Evol Microbiol 55, 1851-1855.

Kimura, M. (1980). A simple method for estimating evolutionary rates of base substitutions through comparative studies of nucleotide sequences. J Mol Evol 16, 111-120.

Kumar, S., Tamura, K. \& Nei, M. (2004). MEGA3: integrated software for molecular evolutionary genetics analysis and sequence alignment. Brief Bioinform 5, 150-163.

Mesbah, M., Premachandran, U. \& Whitman, W. B. (1989). Precise measurement of the $\mathrm{G}+\mathrm{C}$ content of deoxyribonucleic acid by highperformance liquid chromatography. Int J Syst Bacteriol 39, 159-167.

Murray, R. G. E., Doetsch, R. N. \& Robinow, C. F. (1994). Determinative and cytological light microscopy. In Methods for General and Molecular Bacteriology, pp. 21-41. Edited by P. Gerhardt, R. G. E. Murray, W. A. Wood \& N. R. Krieg. Washington, DC: American Society for Microbiology.

Saitou, N. \& Nei, M. (1987). The neighbor-joining method: a new method for reconstructing phylogenetic trees. Mol Biol Evol 4, 406-425.
Sakai, T., Ishizuka, K. \& Kato, I. (2003). Isolation and characterization of a fucoidan-degrading marine bacterium. Mar Biotechnol 5 , 409-416.

Sangwan, P., Chen, X., Hugenholtz, P. \& Janssen, P. H. (2004). Chthoniobacter flavus gen. nov., sp. nov., the first pure-culture representative of subdivision two, Spartobacteria classis nov., of the phylum Verrucomicrobia. Appl Environ Microbiol 70, 5875-5881.

Sangwan, P., Kovac, S., Davis, K. E. R., Sait, M. \& Janssen, P. H. (2005). Detection and cultivation of soil Verrucomicrobia. Appl Environ Microbiol 71, 8402-8410.

Schleifer, K. H. \& Kandler, O. (1972). Peptidoglycan types of bacterial cell walls and their taxonomic implications. Bacteriol Rev 36, 407-477.

Shieh, W. Y. \& Jean, W. D. (1998). Alterococcus agarolyticus, gen. nov., sp. nov., a halophilic thermophilic bacterium capable of agar degradation. Can J Microbiol 44, 637-645.

Thompson, J. D., Gibson, T. J., Plewniak, F., Jeanmougin, F. \& Higgins, D. G. (1997). The CLUSTAL_X windows interface: flexible strategies for multiple sequence alignment aided by quality analysis tools. Nucleic Acids Res 25, 4876-4882.

Vandekerckhove, T. T. M., Willems, A., Gillis, M. \& Coomans, A. (2000). Occurrence of novel verrucomicrobial species, endosymbiotic and associated with parthenogenesis in Xiphinema americanumgroup species (Nematoda, Longidoridae). Int J Syst Evol Microbiol 50, 2197-2205.

Weisburg, W. G., Barns, S. M., Pelletier, D. A. \& Lane, D. J. (1991). $16 S$ ribosomal DNA amplification for phylogenetic study. J Bacteriol 173, 697-703.

Yokota, A., Tamura, T., Nishii, T. \& Hasegawa, T. (1993). Kineococcus aurantiacus gen. nov., sp. nov., a new aerobic, gram-positive, motile coccus with meso-diaminopimelic acid and arabinogalactan in the cell wall. Int J Syst Bacteriol 43, 52-57. 